\title{
Phenotypic analysis of pregnancy effect on milk, fat, and protein yields of Canadian Ayrshire, Jersey, Brown Swiss, and Guernsey breeds
}

\author{
S. Loker, ${ }^{\star}$ F. Miglior, $\dagger \ddagger^{1}$ J. Bohmanova, ${ }^{\star}$ J. Jamrozik, ${ }^{*}$ and L. R. Schaeffer ${ }^{\star}$ \\ ${ }^{*}$ Centre for Genetic Improvement of Livestock, Department of Animal and Poultry Science, University of Guelph, Guelph, ON, Canada N1G 2W1 \\ †Dairy and Swine Research and Development Centre, Agriculture and Agri-Food Canada, Sherbrooke, QC, Canada J1M 1 Z3 \\ $\mp$ Canadian Dairy Network, Guelph, ON, Canada N1K 1E5
}

\section{ABSTRACT}

Pregnancy has a negative impact on milk production in dairy cattle. Estimates of the effects of pregnancy are required in genetic evaluation models. Test-day records of Ayrshire, Jersey, Brown Swiss, and Guernsey breeds were analyzed phenotypically for the effect of pregnancy using 4 different models. Milk, fat, and protein yields were analyzed separately. The first model used a fourth-order Legendre polynomial regression on days in milk within classes of $10 \mathrm{~d}$ open. The second model fitted stage of pregnancy within days open classes to investigate the possible interaction between lactation stage and gestation stage. The third model included a fourth-order Legendre polynomial regression on days pregnant. In the fourth model, test-day records were divided into stage of pregnancy classes. Given that the effect of pregnancy was significant for all models, and that the adjusted R-squared values were consistent across the models, implying that the models for each trait fitted equally well within breeds, models were therefore compared based on the practicality of the results. Analysis of the first model indicated that milk production for cows with $\leq 180 \mathrm{~d}$ open tended to have low yields in the last part of lactation. Cows with longer days open, however, had proportionally higher milk yield throughout lactation, suggesting a possible confounding effect of production level with days open effects. Results from the analysis involving the second model illustrated that there was no apparent interaction between lactation stage and gestation stage. Results from the third and fourth models showed that milk and fat yields began to decline after about 4 mo of pregnancy for all breeds, and protein yield began to decline after about 2 mo of pregnancy for all breeds. A lack of records during the final $60 \mathrm{~d}$ of pregnancy (the typical dry period) severely limited the third model, as pregnancy effects could not be estimated accurately.

Received June 4, 2008.

Accepted October 20, 2008.

${ }^{1}$ Corresponding author: Miglior@cdn.ca
This problem was lessened, however, with the fourth (stage of pregnancy) model, because test-day records for cows $\geq 210 \mathrm{~d}$ pregnant were grouped together, allowing for a moderate number of test-day records in the final class of days pregnant. Because the stage of pregnancy model showed a decline in production that increased as gestation progressed, and because there was not a lack of test-day records at the end of pregnancy, the fourth model provided the most realistic estimate of the effect of pregnancy on milk production. Further investigation is needed into the incorporation of stage of pregnancy effects into genetic evaluations.

Key words: test-day model, days open, days pregnant, stage of pregnancy

\section{INTRODUCTION}

Genetic evaluation of dairy cattle for production traits is performed in Canada by using a multiple-trait, random regression test-day (TD) model known as the Canadian Test-Day Model (CTDM; Schaeffer et al., 2000). This model does not currently account for the environmental influence of pregnancy. If pregnancy significantly affects production and the impact differs because of differences in date of conception, then it would affect differences in yields between cows.

Pregnancy effects refer to how the process of gestation influences milk production traits. Hormones released as a result of pregnancy cause an increased regression of the mammary gland (Bachman et al., 1988; Coulon et al., 1995; Brotherstone et al., 2004; Akers, 2006). These hormones are released from the fetal placental unit at around $100 \mathrm{~d}$ into gestation (Bachman et al., 1988). As the fetus grows larger, its nutrient demands increase (Brotherstone et al., 2004), which leaves less nutrients and energy to be partitioned toward the production of milk. The effect of pregnancy is small at the beginning of gestation and becomes larger at later stages of gestation when growth and nutrient requirements of the conceptus increase. These effects are nongenetic, and should not be included in the genetic representation of the cow's ability to produce milk. 
The decline in milk yield as a result of pregnancy begins after 4 or 5 mo of pregnancy (Bachman et al., 1988; Olori et al., 1997; Roche, 2003). On average, Canadian dairy cattle breeds conceive at approximately 4 mo of lactation (Canadian Dairy Network, 2004). For Canadian Holstein multiparous cows, Jamrozik et al. (2005) found that the average interval from calving to first service was $87.1 \mathrm{~d}$, and the average interval from first service to conception was $32.5 \mathrm{~d}$. Because milk production begins to decline at 4 or 5 mo into gestation, and because Canadian dairy cattle conceive at approximately $4 \mathrm{mo}$ into lactation, many cows will begin to experience pregnancy effects that significantly influence production traits before 305 DIM. Thus, TD records may be negatively influenced by pregnancy for many cows.

Another important consideration is the possible interaction between stage of lactation and stage of gestation. Olori et al. (1997) found that the effect of pregnancy was greater in midlactation than in late lactation $(P<0.05)$. Conversely, Auran (1974) found that the depression of milk yield from the fifth to the sixth month of gestation was greater in the tenth month of production compared with earlier stages of lactation, and concluded that there was a significant $(P<$ 0.01 ) interaction between stage of lactation and stage of gestation. Sharma et al. (1990), however, did not find a significant interaction between stage of lactation and stage of pregnancy for any of the milk production traits studied, including milk, fat, and protein yield $(P$ $>0.05)$.

Assuming pregnancy has a significant effect on dairy cattle production before 305 DIM, accounting for this effect would remove an environmental influence on production from the calculation of an animal's genetic merit. Accuracy of EBV should, therefore, increase after accounting for pregnancy. Including pregnancy effects in future genetic evaluations will allow the use of TD records beyond 305 DIM to calculate EBV because pregnancy will affect most TD records taken after 305 DIM. However, adding a new effect to the model increases the complexity of the model, which increases the computing time required to complete genetic evaluations. Conception dates will need to be determined, and so accurate insemination records will be required. New variance components for the CTDM might need to be estimated if pregnancy effects are added to the model.

If pregnancy has a significant environmental impact on the TD yields of Canadian dairy cattle, then it should be included in the CTDM. The CTDM does not currently account for pregnancy effects, which may cause an underestimation of breeding values for pregnant cows. Given that cows may differ in the stage of lactation during which they become pregnant, the problem of bias may be with cows that have either very short or very long days open (DO). Updating the CTDM to account for pregnancy effects will increase the accuracy of the genetic evaluations of Canadian cows and bulls. More accurate genetic evaluations will allow for improved selection for breeding programs, as well as a more accurate representation of Canadian genetics, which may be important for international evaluations as well as for the exportation of genetics. Before a pregnancy effect is included in the CTDM, its influence on production traits must be verified, and methods of accounting for pregnancy must be explored. The objective of this study, therefore, was to perform a phenotypic analysis to quantify the effect of pregnancy on milk production traits for 4 different dairy cattle breeds using 4 different models. Results from this study will determine the need for correcting for pregnancy in national genetic evaluations, and may describe useful methodology to account for an effect of pregnancy that would be expected to bias evaluations.

\section{MATERIALS AND METHODS}

\section{Data}

Data were TD records of Canadian Ayrshire (AY), Jersey (JE), Brown Swiss (BS), and Guernsey (GU) breeds. Breeds were analyzed separately, and parities 1,2 , and 3 were analyzed separately. Holstein records were analyzed in a separate study by Bohmanova et al. (2008a,b). Test-day data consisted of 3,374,706 records on 193,705 cows calved from 1987 to 2007. Table 1 contains the distribution of TD records among breeds and parities for milk yield (number of TD records were similar across traits). Only first-, second-, and thirdparity TD records with DIM $\geq 5$ and $\leq 365$ were used.

Data included days pregnant and DO information for each TD record. Lactation records of second, third, and fourth parities were used to validate the conception date during the previous lactation. Insemination records were used to determine conception dates so that days pregnant and DO information could be calculated and included in the TD record data. Mean gestation length was assumed to be $280 \mathrm{~d}$ for AY and JE and $285 \mathrm{~d}$ for BS and GU (Bohmanova et al., 2006). Conception dates were assigned as the last date of insemination within $280 \pm 15$ or $285 \pm 15$ d before calving. Otherwise, cows without insemination records were assigned a conception date of calving date minus 280 or 285 d, depending on breed. For animals with incomplete lactations (i.e., lactation still in progress when the data set ended in 2007), the animal was assumed to have conceived at the last available insemination record. If 
Table 1. Numbers of test-day records and cows in lactations 1,2 and 3 by breed ${ }^{1}$

\begin{tabular}{lccccccc}
\hline & \multicolumn{2}{c}{ Number of test-day records } & & \multicolumn{3}{c}{ Number of cows } \\
\cline { 2 - 5 } \cline { 7 - 8 } Breed & Lactation 1 & Lactation 2 & Lactation 3 & & Lactation 1 & Lactation 2 & Lactation 3 \\
\hline AY & 861,906 & 560,099 & 444,083 & & 99,452 & 65,950 & 50,068 \\
JE & 509,454 & 345,820 & 254,968 & & 63,721 & 43,696 & 31,378 \\
BS & 100,463 & 65,307 & 55,580 & & 12,267 & 8,061 & 6,312 \\
GU & 73,856 & 45,261 & 31,453 & & 8,726 & 5,506 & 3,687 \\
\hline
\end{tabular}

${ }^{1} \mathrm{AY}=$ Ayrshire; JE $=$ Jersey; BS = Brown Swiss; and GU = Guernsey.

an insemination record was unavailable for an animal, 2 assumptions were made: the animal did not conceive if the previous calving occurred before 2006 (i.e., the animal had a year or more to conceive and calve, but did not), or the animal was pregnant because the previous calving occurred after 2006 and so the subsequent calving would have occurred after the end of the data set. If the cow was assumed pregnant, conception was assumed to occur at 130 DIM.

Each TD record was assigned an age-season class. Records were assigned to 1 of 7 age classes for parity 1 , 6 classes for parity 2 , and 5 classes for parity 3 . Similar to Schaeffer et al. (2000), 2 seasons of calving were used, with April through September defined as season 1, and October through March defined as season 2.

\section{Days Open}

Because pregnancy effects begin at different stages of lactation depending on when a cow conceives, DO was used in a model to investigate the impact of pregnancy on production traits. Test-day records were grouped into DO classes. Animals that did not have a subsequent calving and lactation were assumed to never have been pregnant during the lactation. If these animals could have become pregnant, but had an abortion or were culled, the assumption was that these animals were not pregnant long enough for pregnancy to have had any influence on production. Never-pregnant cows were grouped together in the DO analysis. Class 1 included TD records for cows that were $>1$ and $\leq 60$ DO. Class 9 included TD records for cows that were $>270$ DO and $\leq 305$ DO, and class 10 included TD records for cows over 305 DO. The remaining DO classes (2-8) consisted of 30-d intervals. The purpose of this model was to study the impact of DO on milk production. The distribution of TD records within each DO class is given in Table 2 for the 4 breeds. Solutions for DO effects on milk, fat, and protein yields were used to plot DO curves by DIM.

\section{Stage of Pregnancy}

Two models for stage of pregnancy were a) polynomial regression on days pregnant; and b) classes of days pregnant. A total of 8 pregnancy classes of 30-d intervals were created, with the eighth class including all cows over $210 \mathrm{~d}$ pregnant. Test-day records of cows that were never pregnant were allocated to the ninth class. Figures 1 and 2 illustrate the distribution of milk yield TD records throughout gestation for the AY breed for days pregnant and classes of days pregnant, respectively.

\section{Interaction Between Stage of Lactation and Stage of Gestation}

Classes of DO and classes of days pregnant were used. For example, 2 cows within the same stage of pregnancy may be at different stages of lactation and, therefore, have different DO. The TD records taken at any particular stage of pregnancy for these 2 animals would therefore always have different DO classes assigned to them. The purpose of this model was to study milk production as pregnancy progressed within DO classes. This was to determine if the decline in milk production caused by pregnancy differed depending on the stage of lactation of the cow. Solutions for interaction effects on milk, fat, and protein yield were used to plot DO curves by days pregnant. Days pregnant, in this case, was calculated by taking the average days pregnant within each stage of pregnancy class.

\section{Models}

Four fixed-effects models were used to study the phenotypic impact of pregnancy on dairy cattle production traits (milk, fat, and protein yield). Model 1 used a Legendre polynomial regression on DIM within DO classes to account for pregnancy by separating cows that experience the effects of pregnancy at different stages of lactation.

The equation for model 1 was

$$
y_{i j k l}=\operatorname{htd}_{i}+\sum_{j=0}^{4} \phi_{j}(t) \cdot \operatorname{aps}_{j k}+\sum_{j=0}^{4} \phi_{j}(t) \cdot \mathrm{do}_{j l}+e_{i j k l},
$$

where $y_{i j k l}$ is the TD production trait record (either milk, fat, or protein yield); $\operatorname{htd}_{i}$ is the $i$ th herd TD ef- 


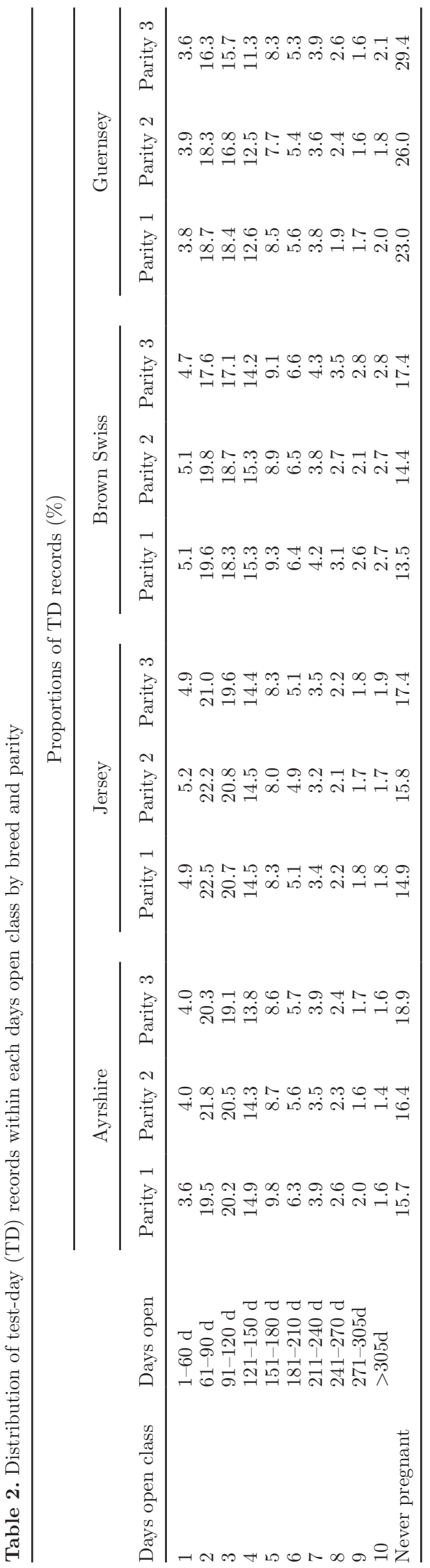

fect; $\operatorname{aps}_{j k}$ is the $j$ th regression coefficient for the $k$ th age-season class; $\mathrm{do}_{j l}$ is the $j$ th regression coefficient of the $l$ th DO class; $\phi_{j}$ is the $j$ th Legendre polynomial for days in milk $(t)$; and $e_{i j k l}$ is the random residual.

Model 2 included classes of days pregnant fitted within DO classes. This allowed production to be plotted over the course of gestation for each DO class.

The equation for model 2 was

$$
y_{i j k l}=\operatorname{htd}_{i}+\sum_{j=0}^{4} \phi_{j}(t) \cdot \operatorname{aps}_{j k}+\mathrm{do}: \operatorname{dp}_{l m}+e_{i j k l m},
$$

where do: $\mathrm{dp}_{l m}$ are classes of days pregnant fitted within days open classes.

Model 3 included a regression of Legendre polynomials on days pregnant. Let dp represent the regression coefficient for days pregnant, then the equation for model 3 was

$$
y_{i j k}=\operatorname{htd}_{i}+\sum_{j=0}^{4} \phi_{j}(t) \cdot \operatorname{aps}_{j k}+\sum_{j=0}^{4} \phi_{j}(\mathrm{dp})+e_{i j k} .
$$

Model 4 used days pregnant divided into classes rather than as a covariate. The equation for model 4 was

$$
y_{i j k l}=\operatorname{htd}_{i}+\sum_{j=0}^{4} \phi_{j}(t) \cdot \operatorname{aps}_{j k}+\mathrm{dp}_{l}+e_{i j k l},
$$

where $\mathrm{dp}_{l}$ is the $l$ th class of days pregnant.

The SAS procedure GLM (SAS Institute, 2007) was used to obtain the significance of the 4 different approaches to quantify the effect of pregnancy. The software BLUPF90 (Misztal, 1999) was used to estimate the solutions for effects in the models. Solutions for effects of DO, DO by stage of pregnancy, days pregnant, and stage of pregnancy were plotted to study the impact of pregnancy on production traits (milk, fat, and protein yields) as well as the feasibility of the eventual use of these models in the CTDM. None of the models included the cow genetic effect or permanent environmental effect.

Because the 4 breeds under investigation will not produce the same levels of milk, fat, and protein, the absolute and percentage decline in milk, fat, and protein yields as pregnancy progressed was also investigated for all 4 breeds. Mean yields were calculated for each stage of pregnancy in each parity. Solutions from model 4 were used as decline in yield for a given stage of pregnancy. Percentage decline at a particular stage of 


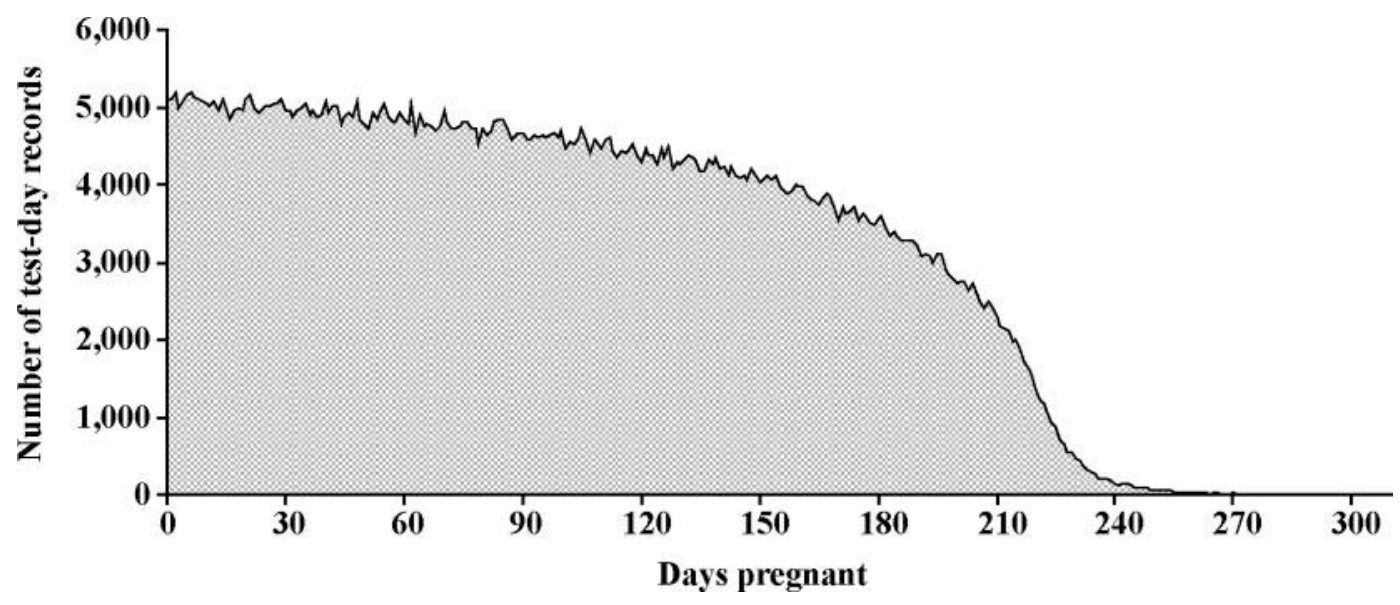

Figure 1. Number of milk yield test-day records for Ayrshire cows by days pregnant.

gestation was calculated by dividing decline in yield by the mean yield for that stage of pregnancy. Percentage decline was averaged across 4 parities. Absolute decline at a particular stage of gestation was calculated by averaging the decline in yield for that gestation stage across 4 parities.

\section{RESULTS AND DISCUSSION}

For all analyses, most effects were significant, with a few exceptions of level of regressor in a small number of trait-parity-breed combinations. Pregnancy effects for the 4 models were found to be significant at a level of $P<0.0001$ for all breeds studied (for each trait and in each parity). Ranges of adjusted R-squared values across all models and within each parity were calculated within each trait, and these ranges were averaged across parities. Adjusted R-squared values ranged between about 0.68 and 0.76 for milk, 0.65 and 0.72 for fat, and 0.63 and 0.74 for protein. Most of the results presented are for Ayrshire only because results were similar across all breeds. Because persistency of cows in first lactation is greater than in older cows (Tessmann et al., 1991), steeper declines in production traits occurred for parities 2 and 3 compared with parity 1 . Otherwise, patterns of decline in production traits were similar across parities. As a consequence, only parity 1 results for some analyses are shown.

\section{Model 1, Days Open}

Figures 3, 4, 5, and 6 show DO curves by DIM for effect of DO on parity 1 milk yield for AY, JE, BS, and GU cows, respectively. Because most cows are given a dry period of $60 \mathrm{~d}$ before calving, the number of TD records decreased drastically for DO classes 1,2 , and 3 at around 280, 310, and 340 DIM, respectively. Consequently, predictions of decline in milk production were not plotted during the dry period, because solutions would not be based on sufficient data. Results were

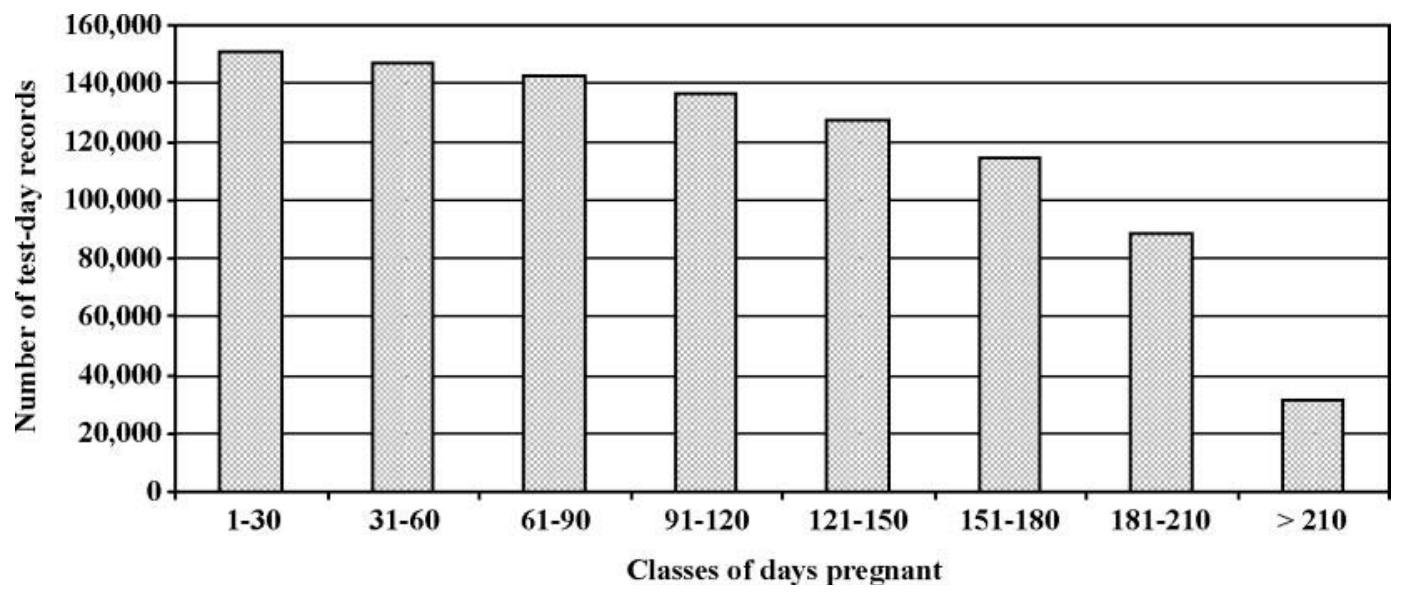

Figure 2. Number of milk yield test-day records for Ayrshire cows by classes of days pregnant. 


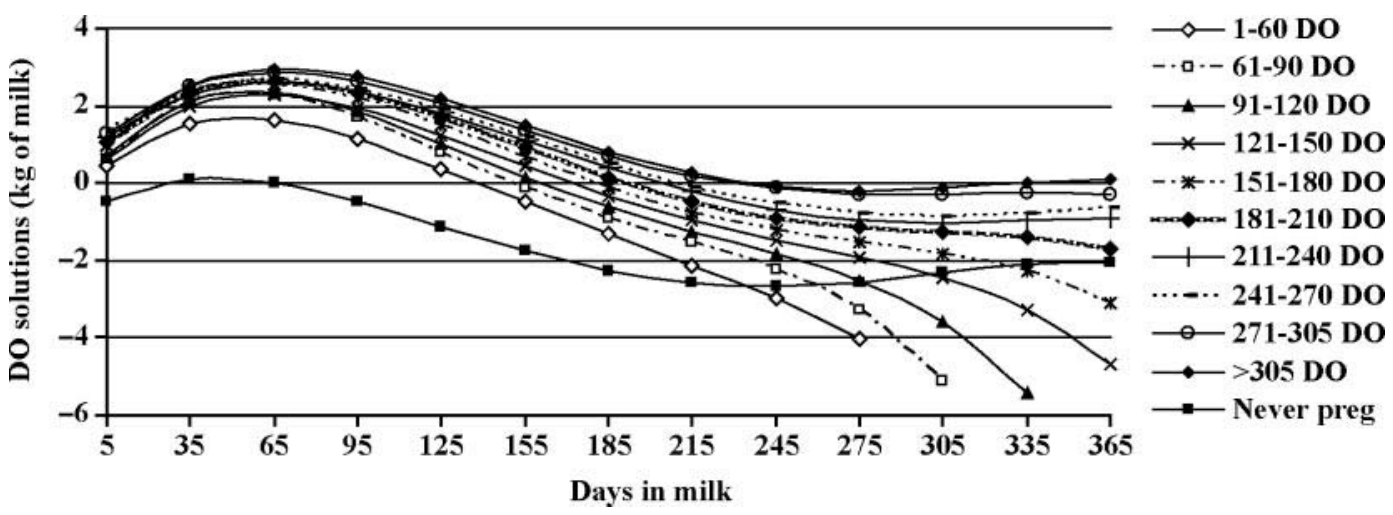

Figure 3. Ayrshire parity 1, days open (DO) effect on milk yield (kg).

similar across traits and parities, although peak yields were not nearly as pronounced for fat and protein as they were for milk (results not shown). Results were similar across all breeds, with slight fluctuations for GU.

Brotherstone et al. (2004) found that accounting for DO significantly improved the goodness of fit of the model to the data for all 4 lactations. Schaeffer and Henderson (1972) divided cows into DO groups of $10 \mathrm{~d}$ per group and found significant differences between DO groups for 305-d milk yield.

Overall, cows in the "never pregnant" class had the least milk production throughout lactation. A possible explanation for this could be that these cows had poor production and producers planned on culling these cows after their lactation, and so did not try to inseminate them. Similarly, Brotherstone et al. (2004) found that the milk production of cows that were never pregnant throughout lactation was lower, and attributed this to possible health problems such as mastitis. This proportionally lower production suggests the presence of a possible confounding effect between production level and DO. Bohmanova et al. (2008b) also found that DO effect was confounded with production level of cows. Danell (1982) found that the effects of DO were significant early in lactation when no decrease in milk yield caused by gestation should occur. This author also suggested a possible confounding effect between DO and milk production level. Conversely, Oltenacu et al. (1980) concluded that 305-d cumulative milk yield associated with differing DO periods did not vary between high- and low-producing cows within lactation.

Milk yield of cows with shorter DO (classes 1 to 5 , between 1 and $180 \mathrm{DO}$ ) showed a larger decline toward the end of lactation compared with the decline of cows with longer DO (greater than $180 \mathrm{DO}$ ) or cows that never became pregnant. Brotherstone et al. (2004) found that rate of milk production decline increased compared with other groups toward the end of lactation only for DO classes 1, 2, and 3 (DO classes consisted of 30-d intervals).

Compared with cows between 1 and 180 DO, the rate of decline in yield at the end of the 365-d lactation period was not as large for any of the classes of cows
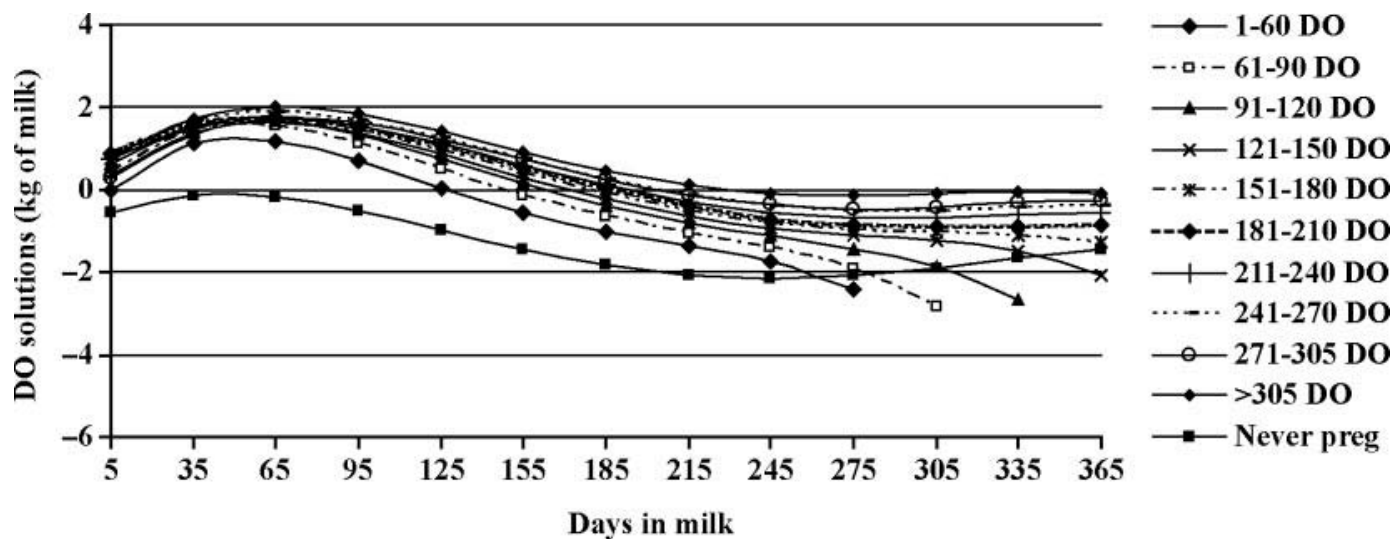

Figure 4. Jersey parity 1, days open (DO) effect on milk yield $(\mathrm{kg})$. 


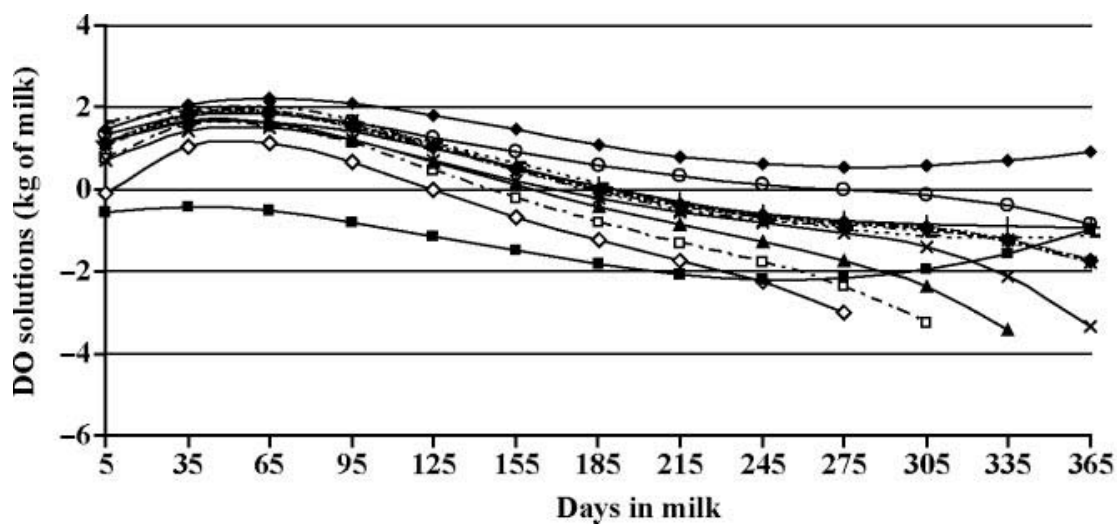

$\multimap-1-60$ DO

-.ロ.- 61-90 DO

$\longrightarrow$ 91-120 DO

* 121-150 DO

$-\cdot * \cdots 151-180$ DO

--๑-- 181-210 DO

— 211-240 DO

…-. 241-270 DO

- 271-305 DO

$\longrightarrow>305$ DO

$\longrightarrow-$ Never preg

Days in milk

Figure 5. Brown Swiss parity 1, days open (DO) effect on milk yield (kg).

that became pregnant later in lactation (for cows $>180$ DO), or for the never pregnant DO class cows. The reason is that pregnancy did not have an effect on the never pregnant DO class cows, and would only have an effect on cows >180 DO after 365 DIM (assuming the producer extends the lactations of these animals beyond $365 \mathrm{~d}$ ). The TD records of cows that conceived later in lactation (>180 DO) were not affected by pregnancy before 365 DIM because these cows had not been pregnant long enough.

The DO curves of cows with longer DO showed proportionally higher yields throughout lactation, suggesting a possible confounding effect between production level and DO. For instance, cows with higher production levels might have poor fertility [because milk production is genetically negatively correlated with fertility (Abdallah and McDaniel, 2000)]. Another possibility is that producers may intentionally prolong the number of DO to extend the lactation of high-producing cows. Schaeffer and Henderson (1972) noted that cows with shorter DO tended to produce less milk (i.e., had a lower 305-d milk yield). They indicated, however, that it was difficult to discern whether cows had fewer DO because they were poor producers, or if they produced less milk because they had fewer DO. Lee et al. (1997) found a significant relationship between DO and 305-d milk yield with higher yielding cows having greater DO, which was estimated to cause an overcorrection bias of up to $70 \%$ (i.e., the estimated effect of pregnancy would be calculated as being much higher than it actually is).

\section{Model 2, Days Open by Stage of Pregnancy}

Solutions for classes of days pregnant fitted within DO classes were used to estimate DO curves for effect on milk yield by days pregnant (Figure 7). Patterns of DO curves were similar for fat and protein yield (results not shown). The rate of decline was only slightly larger for parity 2 and 3 compared with parity 1 . Dividing TD records into DO by classes of days pregnant resulted in so few TD records in each category that differences between parities were not accurately depicted. Patterns of milk, fat, and protein yield decline were similar across
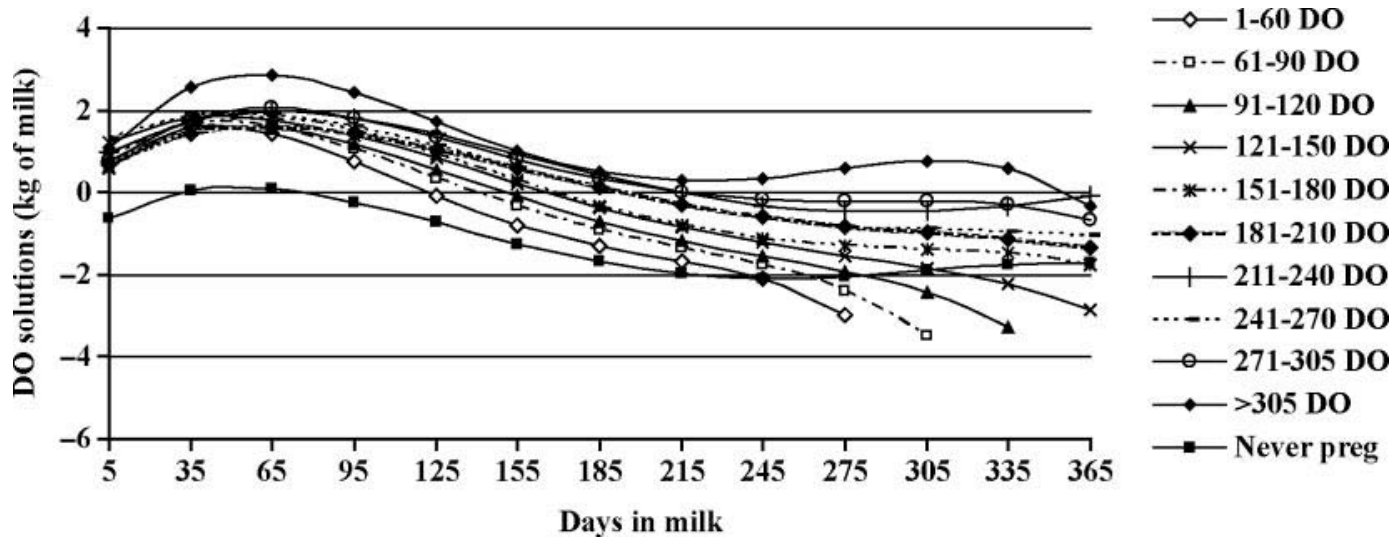

Figure 6. Guernsey parity 1, days open (DO) effect on milk yield (kg). 

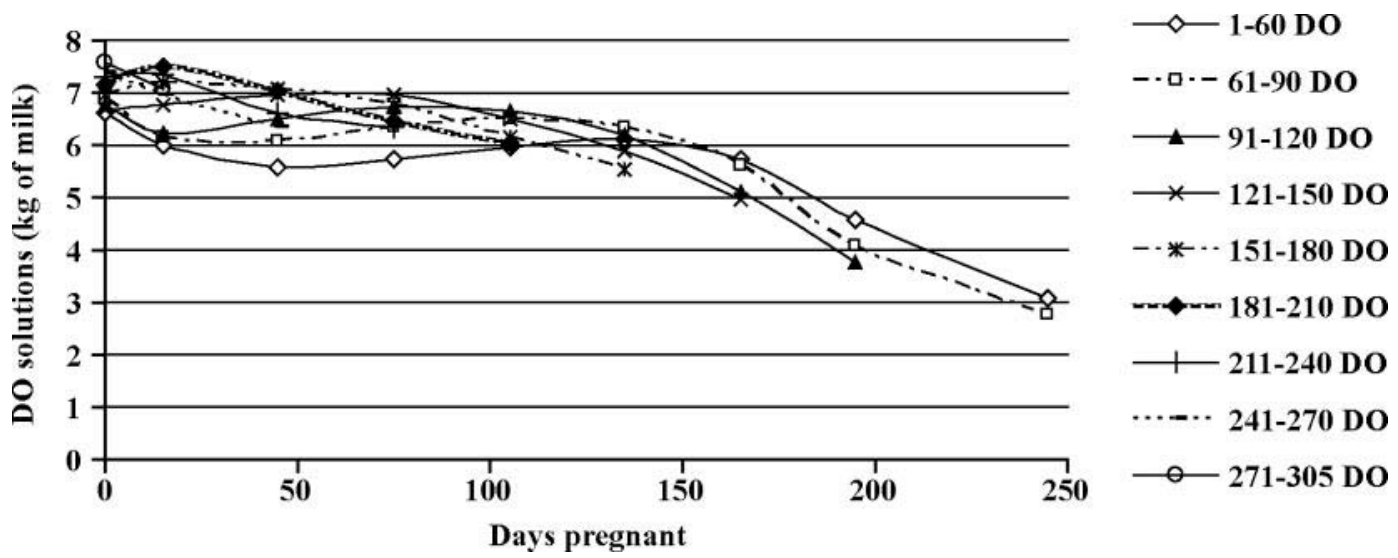

Figure 7. Ayrshire parity 1, days open (DO) effect on milk yield by days pregnant.

all breeds, with slight fluctuations for smaller breeds (BS and GU).

Similar to model 1, DO classes seemed to be confounded with production level, with cows that became pregnant later having greater production. Each DO curve in Figure 7 starts at $0 \mathrm{~d}$ pregnant, and for DO between 1 and 120, the curves began with a decline for the first 30 to $60 \mathrm{~d}$ in gestation. Following this, milk yield began to increase for about 60 to $90 \mathrm{~d}$ before declining again. In the first month or two of gestation, it is possible that endocrine changes associated with the beginning of pregnancy resulted in a small initial decline in production. The effect would likely be more noticeable for animals at the peak of production. Cows that conceive soon after lactation begins may be in a negative energy balance for a short while because of high milk production and endocrine changes.

Stage of lactation can be approximated using DO and stage of pregnancy. For instance, a cow that is open for $60 \mathrm{~d}$ and is $15 \mathrm{~d}$ pregnant is approximately 75 DIM. For every DO class, the decline in milk yield began at relatively the same period of lactation (between 200 and 240 DIM). This indicates that, although the explanatory variable was found to be significant, the decline in production described by this model may include the natural decline in production that occurs at a particular stage of lactation as a result of mammary gland regression independent of pregnancy. Also, all curves had similar slopes. Model 1 showed that DO does model the effect of pregnancy when comparing the rate of production decline of the different DO classes. Results from model 2 illustrate that the rate of decline in production traits is similar among DO classes, showing that the effect of pregnancy is similar across these groups. It is therefore not apparent that there is an interaction effect between stage of lactation and stage of gestation.
Danell (1982) found an interaction between stage of lactation and stage of gestation. Days open classes were included in the model for the analysis of TD yields with 10 TD periods as separate traits. Danell (1982) concluded that after 130 to $140 \mathrm{~d}$ of gestation, pregnancy began to negatively influence milk yield, and that for any given period of gestation, pregnancy effects differed depending on the TD within the lactation. However, Danell (1982) admits the possibility of confounding effects between production level of cows and DO with higher yielding cows possibly being selected to be bred later.

Auran (1974) analyzed a model for monthly milk yield that included month of pregnancy, month of production, and the interaction between them. The interaction was found to be significant $(P<0.01)$.

\section{Model 3, Days Pregnant}

The AY breed's results for decline in milk yield as gestation progressed are presented in Figure 8 (results not shown for fat and protein yield loss). Declines in parity 2 and 3 were steeper compared with parity 1 . Because of lack of records, GU, the smallest breed in the analysis, showed slight fluctuations in results.

The decrease in milk yield began at around $120 \mathrm{~d}$ pregnant. Results were similar for fat yield loss. The decline in protein yield began sooner, at around $60 \mathrm{~d}$ pregnant. Milk yield begins to decline after 4 or 5 mo of pregnancy (between 120 and $150 \mathrm{~d}$ pregnant; Bachman et al., 1988; Olori et al., 1997; Roche, 2003).

Roche (2003) studied twins for the effects of pregnancy, comparing pregnant cows to their nonpregnant twins. The decline in milk yield was found to be significant at around 5 mo of pregnancy (33 wk into lactation). Roche (2003) found that the decline in fat and protein yields were not significant until 168 d of pregnancy (approxi- 


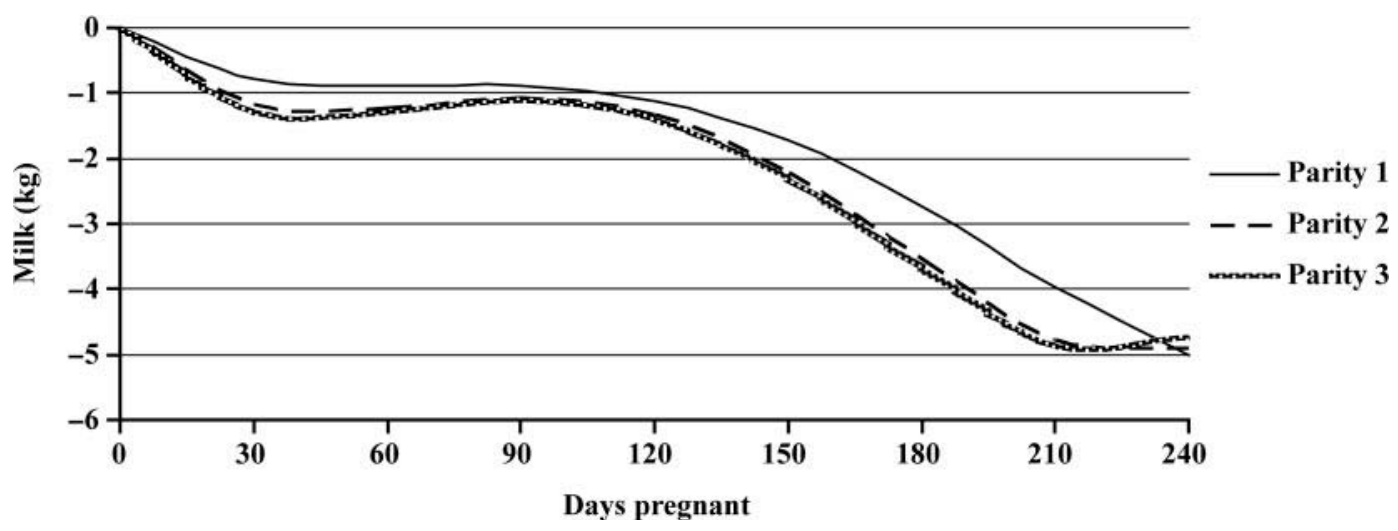

Figure 8. Milk yield decline as pregnancy progresses for the Ayrshire breed by parity, plotted using estimates of effect of days pregnant from model 3 .

mately 36 wk into lactation). Comparatively, protein decline caused by pregnancy began much sooner in the current study, and the biological reason for this is not apparent. Bohmanova et al. (2008b) performed a similar study on Holstein data, and found that a steep decline in milk and protein yield began after approximately 4 mo of pregnancy and fat yield began to decline after about 5 mo of pregnancy.

There was a decline in milk yield from $0 \mathrm{~d}$ pregnant to $30 \mathrm{~d}$ pregnant (Figure 8). Most cows in the data set had few DO (with DO $\leq 150$; Table 2) and the initial decline of milk, fat, and protein yield may be caused by a negative energy balance for cows at the beginning of lactation. As previously mentioned, endocrine changes associated with the beginning of gestation may contribute to the negative energy balance. This initial decline could also be an artifact of fitting a quadratic regression on days pregnant.

The average gestation length for AY cattle was found to be approximately $281 \mathrm{~d}$ in this study. Producers usu- ally dry off cows for $60 \mathrm{~d}$ before calving, so very few TD records remained after around $225 \mathrm{~d}$ of pregnancy (Figure 1). Solutions based on TD records taken after 225 d of pregnancy are not as accurate, and may cause fluctuations in the resulting yields.

\section{Model 4, Stage of Pregnancy}

The AY declines in milk, fat, and protein yield as gestation progressed are presented in Figures 9, 10 and 11, respectively. Declines in parity 2 and 3 were steeper compared with parity 1 across the 4 traits. Because of lack of records, GU, the smallest breed in the analysis, showed slight fluctuations in results.

There was decline in yields at the very beginning of pregnancy; this was shown to be true for models 2 and 3 as well, and was postulated to be a negative energy balance earlier in lactation (when milk production is at its highest), possibly resulting from endocrine changes associated with the start of pregnancy. The decrease in

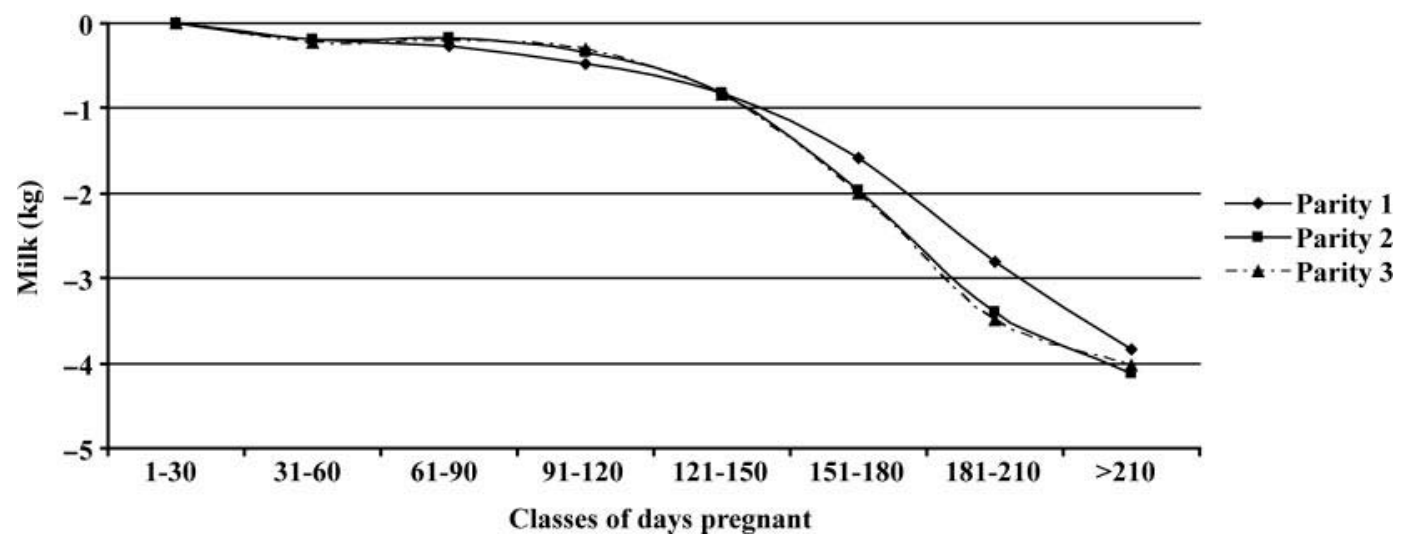

Figure 9. Milk yield decline as pregnancy progresses for the Ayrshire breed by parity, plotted using estimates of effect of stage of pregnancy from model 4 . 


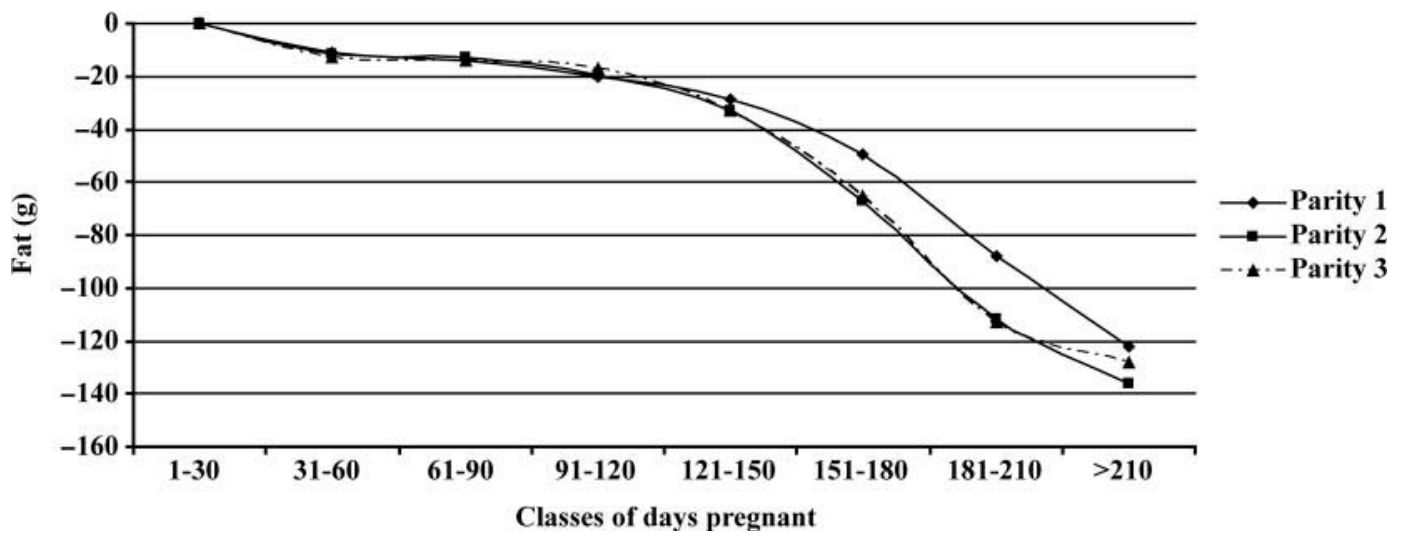

Figure 10. Fat yield decline as pregnancy progresses for the Ayrshire breed by parity, plotted using estimates of effect of stage of pregnancy from model 4.

milk and fat yield for all 4 breeds began in the fourth class of days pregnant, at approximately the fourth month of pregnancy. The decline in protein yield began sooner, at approximately 2 mo of pregnancy.

Model 4 estimates at the eighth class of days pregnant were greater than expected for parities 2 and 3, though not as drastically high as was seen for the 240th day pregnant yields estimated from model 3. Because the eighth class incorporated TD records for cows $>210$ $\mathrm{d}$ pregnant, there were more TD records available in this last class (Figure 2) compared with the TD records available for each of the final $60 \mathrm{~d}$ of pregnancy (Figure 1 ). This would explain why model 4 had a much smaller fluctuation in yield loss at the end of pregnancy compared with model 3 .

Mammary gland regression independent of pregnancy may be a confounding effect in models 3 and 4 . There is a degree of mammary gland regression that occurs as lactation progresses, whether or not a cow becomes pregnant (Olori et al., 1997). Increased mammary gland regression occurs with pregnancy, as stated previously, caused by the release of pregnancy hormones (Bachman et al., 1988; Coulon et al., 1995; Brotherstone et al., 2004; Akers, 2006). Therefore, declining milk production at the end of lactation includes a combination of the effects of pregnancy, as well as mammary gland regression.

\section{Comparison Among Breeds}

Average decline in daily milk, fat, and protein yields by stage of pregnancy are presented in Table 3. Percentage declines in AY traits were nearly twice as high as those of the JE breed. Until $150 \mathrm{~d}$ pregnant, percentage yield declines were very similar between AY, BS, and GU for all 4 traits. From 151 d pregnant, however, AY percentage decline in milk, fat, and protein was much higher compared with respective BS and GU decline. Percentage decline in milk, fat, and protein yields was similar throughout pregnancy between BS and GU, and

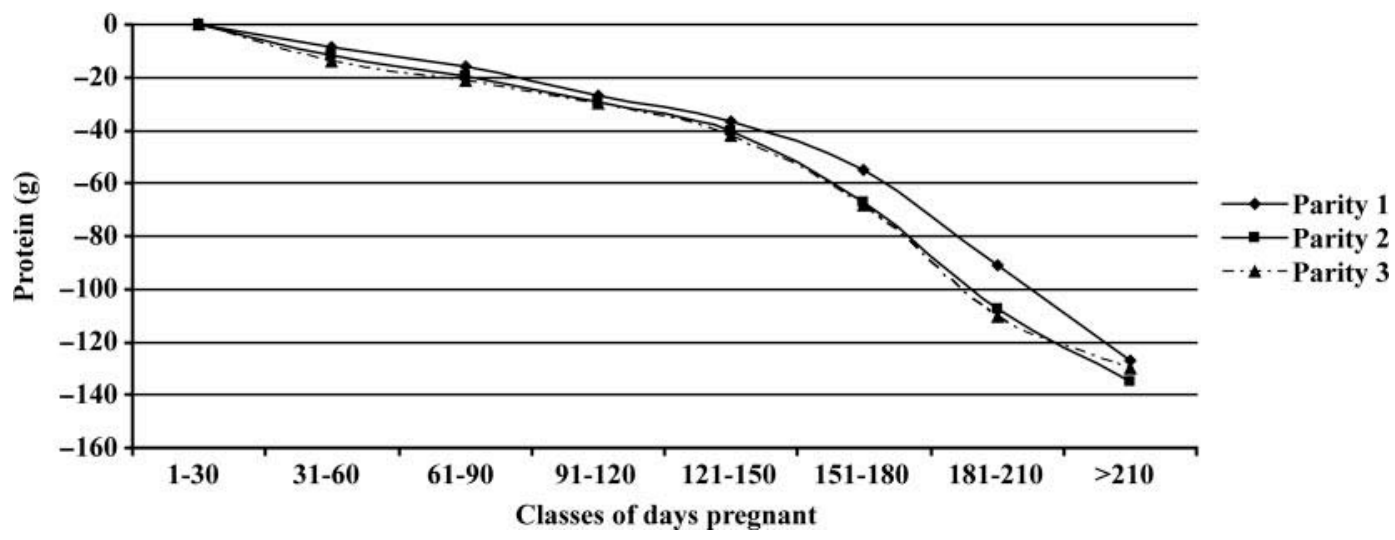

Figure 11. Protein yield decline as pregnancy progresses for the Ayrshire breed by parity, plotted using estimates of effect of stage of pregnancy from model 4. 
Table 3. Average daily milk, fat, and protein yield loss by stage of pregnancy

Percentage decline $(\%)$

\begin{tabular}{|c|c|c|c|c|c|c|c|c|c|c|c|c|}
\hline \multirow[b]{2}{*}{$\begin{array}{l}\text { Classes of } \\
\text { days pregnant }\end{array}$} & \multicolumn{4}{|c|}{ Milk } & \multicolumn{4}{|c|}{ Fat } & \multicolumn{4}{|c|}{ Protein } \\
\hline & Ayrshire & Jersey & $\begin{array}{l}\text { Brown } \\
\text { Swiss }\end{array}$ & Guernsey & Ayrshire & Jersey & $\begin{array}{l}\text { Brown } \\
\text { Swiss }\end{array}$ & Guernsey & Ayrshire & Jersey & $\begin{array}{l}\text { Brown } \\
\text { Swiss }\end{array}$ & Guernsey \\
\hline $1-30$ & 0.0 & 0.0 & 0.0 & 0.0 & 0.0 & 0.0 & 0.0 & 0.0 & 0.0 & 0.0 & 0.0 & 0.0 \\
\hline $31-60$ & 0.0 & 0.0 & 0.0 & 0.0 & 0.0 & 0.0 & 0.0 & 0.0 & 1.5 & 0.9 & 1.2 & 1.7 \\
\hline 61-90 & 0.0 & 0.0 & 0.0 & 0.0 & 0.0 & 0.0 & 0.0 & 0.0 & 2.7 & 1.3 & 1.9 & 2.7 \\
\hline $91-120$ & 1.1 & 0.2 & 1.1 & 1.4 & 1.5 & 0.8 & 1.4 & 1.8 & 4.5 & 2.3 & 3.6 & 4.4 \\
\hline $121-150$ & 3.7 & 2.5 & 3.5 & 3.3 & 3.2 & 2.2 & 3.3 & 2.5 & 6.6 & 4 & 5.9 & 5.7 \\
\hline $151-180$ & 10.7 & 6.6 & 7.4 & 7.7 & 7.7 & 4.7 & 5.4 & 5.1 & 11.3 & 6.5 & 8.7 & 8.7 \\
\hline $181-210$ & 22.5 & 12.4 & 13.9 & 14.9 & 15.8 & 8.7 & 9.6 & 9.8 & 20.6 & 11.2 & 14.4 & 15.1 \\
\hline \multirow[t]{3}{*}{$>210$} & 32.2 & 17.3 & 20.6 & 23.2 & 22.1 & 12.3 & 14.7 & 15 & 29.5 & 15.9 & 21.4 & 23.7 \\
\hline & \multicolumn{12}{|c|}{ Absolute decline $(\mathrm{kg})$} \\
\hline & \multicolumn{4}{|c|}{ Milk } & \multicolumn{4}{|c|}{ Fat } & \multicolumn{4}{|c|}{ Protein } \\
\hline $\begin{array}{l}\text { Classes of } \\
\text { days pregnant }\end{array}$ & Ayrshire & Jersey & $\begin{array}{l}\text { Brown } \\
\text { Swiss }\end{array}$ & Guernsey & Ayrshire & Jersey & $\begin{array}{l}\text { Brown } \\
\text { Swiss }\end{array}$ & Guernsey & Ayrshire & Jersey & $\begin{array}{l}\text { Brown } \\
\text { Swiss }\end{array}$ & Guernsey \\
\hline $1-30$ & 0.00 & 0.00 & 0.00 & 0.00 & 0.000 & 0.000 & 0.000 & 0.000 & 0.000 & 0.000 & 0.000 & 0.000 \\
\hline $31-60$ & 0.00 & 0.00 & 0.00 & 0.00 & 0.000 & 0.000 & 0.000 & 0.000 & 0.011 & 0.007 & 0.010 & 0.012 \\
\hline 61-90 & 0.00 & 0.00 & 0.00 & 0.00 & 0.000 & 0.000 & 0.000 & 0.000 & 0.019 & 0.008 & 0.015 & 0.018 \\
\hline $91-120$ & 0.18 & 0.00 & 0.22 & 0.24 & 0.011 & 0.006 & 0.012 & 0.015 & 0.029 & 0.015 & 0.027 & 0.028 \\
\hline $121-150$ & 0.63 & 0.38 & 0.70 & 0.55 & 0.023 & 0.018 & 0.028 & 0.021 & 0.040 & 0.025 & 0.043 & 0.035 \\
\hline $151-180$ & 1.65 & 1.02 & 1.40 & 1.18 & 0.052 & 0.038 & 0.044 & 0.041 & 0.064 & 0.040 & 0.061 & 0.050 \\
\hline $181-210$ & 3.03 & 1.78 & 2.39 & 2.14 & 0.096 & 0.067 & 0.072 & 0.074 & 0.103 & 0.066 & 0.092 & 0.084 \\
\hline$>210$ & 3.79 & 2.30 & 3.22 & 2.94 & 0.120 & 0.089 & 0.102 & 0.102 & 0.131 & 0.088 & 0.125 & 0.117 \\
\hline
\end{tabular}


decline was slightly higher compared with JE decline. When comparing percentage yield decline across the 4 traits within the AY breed, from $151 \mathrm{~d}$ pregnant, milk yield decline was much higher compared with decline in fat. This difference across traits was not seen for the other breeds, perhaps because of differences in production level between AY and the other breeds. For all breeds, percentage decline in milk yield and protein yield were similar after $150 \mathrm{~d}$ pregnant. Had percentage decline in yields been the same across breeds and across traits, one possibility would be to use these percentages as multiplicative adjustment factors that would apply to all 4 breeds and all 4 traits. Absolute decline in milk, fat, and protein yields also show differences across breeds.

Because the effect of pregnancy being investigated is a temporary environmental effect, this study did not include random animal or permanent environmental effects in the models. Not including the genetic effect of the cow should not influence the results. A comparable study with results similar to this study was carried out by Bohmanova et al. (2006), which did not include random animal and permanent environmental effects. Later, Bohmanova et al. (2008b) expanded the analysis to include genetic and permanent environmental effects, estimating pregnancy effect on Holsteins only. In the Holstein breed, differences in pregnancy effects were minimal between the fixed and genetic models (Bohmanova et al., 2006, 2008b). Additionally, results from the current study from Model 4 were similar to results obtained by Bohmanova et al. (2008a). They re-estimated pregnancy effects (using classes of stage of pregnancy of 21d instead of 30d as in the current study) for all Canadian dairy breeds by using a genetic model that included the cow and the permanent environmental effects, and concluded that the pregnancy adjustment factors developed in this study should be used for pre-adjusting milk, fat, and protein TD records in the routine CTDM. The Canadian dairy industry has accepted their recommendations and the Canadian Dairy Network will pre-adjust TD records for pregnancy effects for national genetic evaluations of all Canadian dairy breeds starting in January 2009.

\section{CONCLUSIONS}

Pregnancy effects in all models were statistically significant $(P<0.0001)$. Furthermore, adjusted R-squared values were consistent across models, implying that the models for each trait fitted equally well within breeds. Model 1 showed that pregnancy does affect TD yields, but the effect of DO may be confounded with production level. Because of confounding effects, this method of accounting for pregnancy would not be useful for application in the CTDM.

Model 2 showed no apparent interaction between lactation stage and gestation stage. The rate of decline in production within each trait was similar among DO classes.

Including days pregnant in the model demonstrated that an increasing reduction in milk, fat, and protein yield was associated with increasing days pregnant. This model unfortunately cannot account for effects after $225 \mathrm{~d}$ of pregnancy because of an extreme lack of records. Therefore, this method of accounting for pregnancy would not be useful for application in the CTDM.

Model 4 also demonstrated an increasing reduction in milk, fat, and protein yields as pregnancy progressed. Unlike the days-pregnant model, however, the stageof-pregnancy model did not lack TD records at the end of pregnancy. Model 4 provides the most realistic estimates of the effect of pregnancy on milk, fat, and protein production, making it the most likely of the 4 methods to be useful for application in the CTDM.

Percentage decline in yields caused by pregnancy were not the same across all breeds for any of the traits studied. Ayrshires experienced the largest percentage decline in milk, fat, and protein yield after approximately the fifth month of pregnancy. Differences in yield decline between JE, BS, and GU were more subtle.

In conclusion, 3 models (model 1 , model 3 , and model 4) demonstrated that pregnancy effects have a significant negative impact on milk, fat, and protein yields of dairy cattle. Of the models studied, the stageof-pregnancy model (model 4) was the most feasible, and it is recommended to use this method to explore the impact of adjusting for pregnancy effect on cow and bull EBV and rankings.

\section{ACKNOWLEDGMENTS}

The authors acknowledge the DairyGen Council of Canadian Dairy Network, and NSERC of Canada for funding this project. Appreciation is extended to Ignacy Misztal (University of Georgia, Athens) for the usage of BLUPF90 software.

\section{REFERENCES}

Abdallah, J. M., and B. T. McDaniel. 2000. Genetic parameters and trends of milk, fat, days open, and body weight after calving in North Carolina herds. J. Dairy Sci. 83:1364-1370.

Akers, R. M. 2006. Major advances associated with hormone and growth factor regulation of mammary growth and lactation in dairy cows. J. Dairy Sci. 89:1222-1234.

Auran, T. 1974. Studies on monthly and cumulative monthly milk yield records. II. The effect of calving interval and stage of pregnancy. Acta Agric. Scand. A 24:339-348. 
Bachman, K. C., M. J. Hayen, D. Morse, and C. J. Wilcox. 1988. Effect of pregnancy, milk yield, and somatic cell count on bovine milk fat hydrolysis. J. Dairy Sci. 71:925-931.

Bohmanova, J., F. Miglior, and J. Jamrozik. 2008a. Estimates of the effect of pregnancy on production traits of Canadian dairy breeds.http:/ /cgil.uoguelph.ca/dcbgc/Agenda0809/Pregnancy.pdf Accessed Sep. 16, 2008.

Bohmanova, J., F. Miglior, J. Jamrozik, L. R. Schaeffer, and S. Loker. 2008b. Accounting for the effect of pregnancy in the Canadian Test Day Model. Presented at Interbull, Annu. Meeting, Niagara Falls, NY, Jun. 2008. http://www.aps.uoguelph.ca/ jbohmano/ publication/Interbull2008.pdf Accessed Sep. 16, 2008.

Bohmanova, J., F. Miglior, M. Kelly, G. Kistemaker, and S. Loker. 2006 Effect of pregnancy on milk yield of Canadian dairy cattle. Dairy Cattle Breeding and Genetics Committee Meeting, University of Guelph, ON, Canada.http://www.aps.uoguelph.ca/ jbohmano/ publication/report_08.pdf Accessed Jul. 16, 2008.

Brotherstone, S., R. Thompson, and I. M. S. White. 2004. Effects of pregnancy on daily milk yield of Holstein-Friesian dairy cattle. Livest. Prod. Sci. 87:265-269.

Canadian Dairy Network. 2004. Interpreting "daughter fertility". http://www.cdn.ca/document.php?id=25. Accessed on Jan. 2008.

Coulon, J. B., L. Pérochon, and F. Lescourret. 1995. Modelling the effect of the stage of pregnancy on dairy cows' milk yield. Anim. Sci. 60:401-408.

Danell, B. 1982. Studies on lactation yield and individual test-day yields of Swedish dairy cows. I. Environmental influence and development of adjustment factors. Acta Agric. Scand. A 32:6581.

Jamrozik, J., J. Fatehi, G. J. Kistemaker, and L. R. Schaeffer. 2005. Estimates of genetic parameters for Canadian Holstein female reproduction traits. J. Dairy Sci. 88:2199-2208.
Lee, J. K., P. M. VanRaden, H. D. Norman, G. R. Wiggans, and T R. Meinert. 1997. Relationship of yield during early lactation and days open during current lactation with 305-day yield. J. Dairy Sci. 80:771-776.

Misztal, I. 1999. Complex models, more data: Simpler programming? Proc. Int. Workshop Comput. Cattle Breed, Tuusala, Finland. Interbull Bull. 20:33-42.

Olori, V. E., S. Brotherstone, W. G. Hill, and B. J. McGuirk. 1997. Effect of gestation stage on milk yield and composition in Holstein Friesian dairy cattle. Livest. Prod. Sci. 52:167-176.

Oltenacu, P. A., T. R. Rounsaville, R. A. Milligan, and R. L. Hintz 1980. Relationship between days open and cumulative milk yield at various intervals from parturition for high and low producing cows. J. Dairy Sci. 63:1317-1327.

Roche, J. R. 2003. Effect of pregnancy on milk production and bodyweight from identical twin study. J. Dairy Sci. 86:777-783.

SAS Institute. 2007. Version 9.1, SAS Inst. Inc., Cary, NC.

Schaeffer, L. R., and C. R. Henderson. 1972. Effects of days dry and days open on Holstein milk production. J. Dairy Sci. 55:107112.

Schaeffer, L. R., J. Jamrozik, G. J. Kistemaker, and J. Van Doormaal. 2000. Experience with a Test-Day Model. J. Dairy Sci. 83:11351144.

Sharma, A. K., C. J. Wilcox, F. G. Martin, and W. W. Thatcher. 1990. Effects of stage of lactation and pregnancy and their interactions on milk yield and constituents. J. Dairy Sci. 73:1586-1592.

Tessmann, N. J., H. D. Radloff, J. Kleinmans, T. R Dhiman, and L. D Satter. 1991. Milk production response to dietary forage:grain ratio. J. Dairy Sci. 74:2696-2707. 